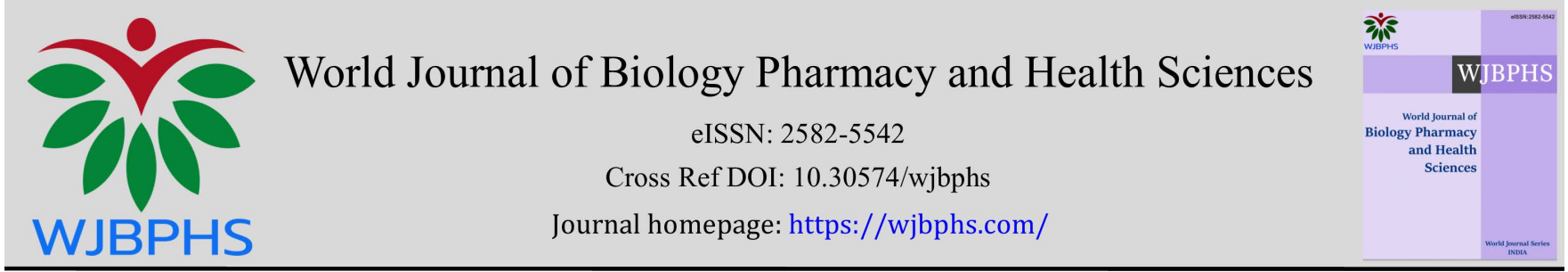

(RESEARCH ARTiCLE)

\title{
Optimal waist circumference cut-off points and prediabetic state as predictors of metabolic syndrome prevalence among Saudi adults in Jeddah city
}

\author{
Bashaer O Alhejaili 1, Rajaa M Al-Raddadi 2, Suhad M Bahijri 3, Khalid D Al-Mutairi 4, Salma Mohammed \\ Yehya Suhluli ${ }^{5}$ and Yehya Mohammed Al-Hejri 5,* \\ ${ }^{1}$ Public Health Administration, Ministry of Health, Madinah, Saudi Arabia. \\ ${ }^{2}$ Department of Community, Medicine, College of Medicine, King Abdulaziz University, Jeddah, Saudi Arabia. \\ ${ }^{3}$ Department of Clinical Biochemistry, Faculty of Medicine, King Abdulaziz University, Jeddah, Saudi Arabia. \\ ${ }^{4}$ Public Health Administration, Ministry of Health, Madinah, Saudi Arabia. \\ ${ }_{5}^{5}$ Public Health Administration, Ministry of Health, Jazan, Saudi Arabia.
}

World Journal of Biology Pharmacy and Health Sciences, 2021, 07(02), 072-084

Publication history: Received on 11 July 2021; revised on 23 August 2021; accepted on 25 August 2021

Article DOI: https://doi.org/10.30574/wjbphs.2021.7.2.0076

\begin{abstract}
With increasing prevalence of metabolic syndrome and absence of local waist circumference cut-off point, it is important to determine the local cut-off point of waist circumference to predict metabolic syndrome.

The aim of this study is to estimate the prevalence of metabolic syndrome among Saudi adults who attend primary health care centers (PHC) in Jeddah city in 2017, and to determine the appropriate waist circumference cut-off value for identifying a person at risk for the metabolic syndrome.

A cross-sectional analytic study was conducted. Results shows; mean age of participants was $30.94 \pm 9.70$ and waist circumference was $96.87 \pm 17.40$ in males and $86.51 \pm 15.30$ in females. The prevalence (CI: $95 \%)$ of pre-diabetes was $16.3 \%(12.9 \%$; $20.1 \%)$, while the prevalence of metabolic syndrome was $\{(95 \% \mathrm{CI}=10.6 \%)(7.80 \% ; 13.8 \%)\}$. Abdominal obesity was the most frequent component of MetS, detected in $60.6 \%$, and followed by high blood pressure in $25.0 \%$. In males, a waist circumference $\geq 93.5 \mathrm{~cm}$ is likely to indicate MetS with $100 \%$ sensitivity and $47.2 \%$ specificity; whereas, in females, optimal waist circumference cut-off was determined as $\geq 83.5 \mathrm{~cm}$, showing $92.3 \%$ sensitivity and $46.4 \%$ specificity. In multivariate logistic regression, extended waist circumference was the strongest predictor of MetS $\{$ OR $(95 \% \mathrm{CI})=3.75(1.30 ; 10.81) ; \mathrm{p}=0.014\}$, followed by the presence pre-diabetes $\{\mathrm{OR}(95 \% \mathrm{CI})=2.31(1.06 ; 5.04)$; $\mathrm{p}=0.035\}$. Further, high educational level was a significant predictor for MetS $\{\mathrm{OR}(95 \% \mathrm{CI})=0.34(0.12 ; 0.99) ; \mathrm{p}=0.047\}$; while age and marital status were not significant predictors.
\end{abstract}

Keywords: Prevalence; Metabolic syndrome; Waist circumference; Saudi adults

\section{Introduction}

A metabolic syndrome (MetS) is a group of several metabolic problems that increase the risk of type 2 diabetes mellitus and cardiovascular diseases [1]. Metabolic syndrome is prevalent all over the world [2], and also among the middle east population [3,4]. Extended waist circumference (WC) is not an obligatory component of MetS while using treatment of dyslipidemia, high BP and high glucose level are considered as risk predictors of MetS [5]. In Saudi Arabia, according to consensus definition, the overall prevalence of MetS was 21,9\% in 2013, and abdominal obesity is the commonest component of MetS, with prevalence 45,9\% [6]. Moreover, a recent study showed that abdominal obesity is a major

\footnotetext{
${ }^{*}$ Corresponding author: Yehya Mohammed Al-Hejri

Public health administration, Ministry of Health, Jazan, Saudi Arabia.
} 
factor in the prediction of prediabetes [7]. Using waist circumference measurement is an applicable and inexpensive way for measuring abdominal obesity and predicting MetS [8].

Furthermore, most of the studies conducted in Saudi Arabia regarding MetS risk does not determine the optimal waist circumference cut-off point for prediction of more than two components of MetS $[9,10]$. This study aims to improve the early detection of MetS among Saudi adult population.

\subsection{Study design}

A cross-sectional analytic study was conducted on the period from January to September 2017 in government primary health care centers in Jeddah city. Jeddah city located in Makkah region in the western part of Saudi Arabia. The population of Jeddah city was about 4,336,145 in 2016, and the number of government primary health care centers in Jeddah city was about 47 centers, distributed in five health sectors in public health administration. This study included adult (aged $\geq 18$ years) men and women who attended primary health care centers in Jeddah. The participants must be fasting for at least 12 hours.

\subsection{Sample size}

The following formula was used to determine the sample size:

$$
N=Z_{1-a \backslash 2}{ }^{2} \times P \times(1-P) \backslash d^{2}
$$

Where $\mathrm{N}=$ sample size;

$\mathrm{Z}_{1-\mathrm{a} \backslash 2}=$ point corresponding to significant level of $5 \%=1.96$;

$\mathrm{p}=$ prevalence of abdominal obesity among adults with metabolic syndrome in Jeddah city $=45.9 \%[6]$;

$q=1-p=54.1 \%$

$\mathrm{d}=$ maximum likely error $(5 \%)$

By setting the level of significance as $95 \%(p \leq 0.05)$, and study power as $80 \%$, the estimated population was $\mathrm{N}=381$.

Adults (men and women) visiting PHCs aged 18 years or above were considered for the study. The patents were approached for recruitment into the project as an initial selection step and asked about their current diagnosed condition. Those stating to be non-diabetic, and free of cancer, a hereditary disorder, heart failure and other cardiovascular diseases, and for women if not pregnant were considered to be legible candidates.

The study was explained to patients in a simple lay language, and once agreed, they were requested to sign an informed consent form. After selection, they were asked for non-fasting condition and were given a later appointment for blood testing.

A blood sample is drawn using butterfly needle into one ethylene diamine tetra acetic acid (EDTA) tube (2.0 mL), and one plain tube $(4.0 \mathrm{~mL})$. The blood samples were collected by PHCs laboratory technician.

Anthropometric measurements (weight, height, waist, and hip circumference), and blood pressure measured. Also, the pre-designed structured questionnaire was be filled by face-to-face interview. The questionnaire was aimed to collect data regarding medical history, medication history, and socio- demographic characteristics.

Numbers of all approached individuals and those who completed the study to determine response rate was noted.

The following tests were carried out in the fasting serum sample (obtained after clotting and centrifugation): Glucose, HbA1c, Triglycerides, and levels HDL- C. Collected samples were placed on ice immediately, and transferred to King Fahd Medical Research Center at the end of each collection session for processing and storage at - $80^{\circ} \mathrm{C}$. The processing and storage were handled by a well-trained laboratory technician. All biochemical tests were performed in one batch at the completion of sample collection.

The study questionnaire contained three parts: 
- Personal data, demographic information, and medical history (including personal history of chronic disease, and a current medication used)

- Anthropometric measurements;

- Blood tests results.

Data were coded, entered and managed using Statistical Package for Social Sciences (SPSS) v.22.

Approval of the study protocol and the data collection was obtained from health authority and Ethical Committee in Jeddah.

\section{Results}

\subsection{Demographic characteristics}

Among 451 recruited patients 436 were included in the study; 15 were diagnosed as diabetics based on FBG or HbA1c. Demographic characteristics showed 64.9\% of males; mean (SD) age was 30.94 (9.70) years, with the male group being relatively younger than female one $\{$ mean $(S D)$ age $=30.02$ (8.93) versus 32.66 (10.80) years; $p=0.006\}$. Majority of the participants achieved university or post-graduate degree, which was almost equal in males (59.2\%) and females (58.8\%), ( $\mathrm{p}=0.408)$. Regarding economic status, $28.9 \%$ had moderate income $(>5,000-10,000 \mathrm{SR})$, and $38.4 \%$ had high or very high income $(>10,000 \mathrm{SR})$, without significant difference between males and females ( $\mathrm{p}=0.221)$. A statistically significant difference was found in the amount of physical activity at work, where males were more likely to have moderate or considerable activity, by comparison to females $(\mathrm{p}=0.000)$. Ethnically, $78.9 \%$ of the participants descended from Arabian tribes, more of males $(86.6 \%)$ than females $(64.7 \%),(p=0.000)$.

\subsection{Clinical characteristics by gender}

Table 1 Anthropomorphic and clinical characteristics by gender

\begin{tabular}{|c|c|c|c|c|}
\hline Parameter & Total $(N=436)$ & $\operatorname{Men}(\mathrm{N}=283)$ & Women $(\mathrm{N}=153)$ & p-value \\
\hline \multicolumn{5}{|l|}{ Medical history } \\
\hline Hypertension & $34(7.8)$ & $15(5.3)$ & $19(12.4)$ & $0.008^{*}$ \\
\hline \multicolumn{4}{|c|}{ Treatment for hypertension } & \multirow{4}{*}{$0.002 *$} \\
\hline No & $415(95.2)$ & $275(97.2)$ & $140(91.5)$ & \\
\hline Yes & $15(3.4)$ & $8(2.8)$ & 7 94.6) & \\
\hline Previously & $6(1.4)$ & $0(0.0)$ & $6(3.9)$ & \\
\hline \multicolumn{5}{|c|}{ Anthropomorphic measurements } \\
\hline Weight (kg) & $77.87(19.31)$ & $83.05(18.98)$ & $68.29(16.01)$ & $0.000^{*}$ \\
\hline Height $(\mathrm{cm})$ & $167.35(9.16)$ & $171.87(6.91)$ & $158.99(6.58)$ & $0.000^{*}$ \\
\hline Body mass index $(\mathrm{kg} / \mathrm{m} 2)$ & $27.70(6.05)$ & $28.09(6.03)$ & $26.97(6.05)$ & 0.065 \\
\hline \multicolumn{5}{|l|}{ BMI (classification) } \\
\hline Underweight & $14(3.2)$ & $8(2.8)$ & $6(3.9)$ & \multirow{6}{*}{0.398} \\
\hline Normal & $136(31.2)$ & $82(29.0)$ & $54(35.3)$ & \\
\hline Overweight & $158(36.2)$ & $105(37.1)$ & $53(34.6)$ & \\
\hline Class I obesity & $75(17.2)$ & $54(19.1)$ & $21(13.7)$ & \\
\hline Class II obesity & $36(8.3)$ & $21(7.4)$ & $15(9.8)$ & \\
\hline Extreme obesity & $17(3.9)$ & $13(4.6)$ & $4(2.6)$ & \\
\hline Waist circumference $(\mathrm{cm})$ & $93.24(17.39)$ & $96.87(17.40)$ & $86.51(15.30)$ & $0.000^{*}$ \\
\hline
\end{tabular}




\begin{tabular}{|l|c|c|c|c|}
\hline Hip circumference (cm) & $106.08(15.37)$ & $106.96(16.54)$ & $104.46(12.82)$ & 0.104 \\
\hline Waist-to-hip ratio & $0.88(0.10)$ & $0.91(0.09)$ & $0.83(0.10)$ & $0.000^{*}$ \\
\hline Clinical examination & $119.12(11.52)$ & $121.59(9.46)$ & $114.56(13.47)$ & $0.000^{*}$ \\
\hline Systolic BP (mm Hg) & $73.95(10.93)$ & $75.31(9.65)$ & $71.42(12.62)$ & $0.000^{*}$ \\
\hline Diastolic BP (mm Hg) & $81(18.6)$ & $56(19.8)$ & $25(16.3)$ & 0.377 \\
\hline High systolic BP, n (\%) & $62(14.2)$ & $41(14.5)$ & $21(13.7)$ & 0.828 \\
\hline High diastolic BP, n (\%) &
\end{tabular}

Values are mean (standard deviation) unless indicated otherwise. The $t$ test was used for continuous variables and the chi-square test for categorical variables; * statistically significant result (p-value<0.05);

Anthropomorphic and clinical characteristics of the total population as well as by gender are presented in Table 1 . The reported mean (SD) BMI= 28.09 (6.03) versus 26.97 (6.05) kg/m², (p=0.065); waist circumference=96.87 (17.40) versus $86.51(15.30) \mathrm{cm},(\mathrm{p}=0.000)$; waist-to-hip ratio=0.91 (0.09) versus $0.83(0.10),(\mathrm{p}=0.000)$ among males versus females, respectively. There were statistically significant differences in both systolic $(p=0.000)$ and diastolic $(p=0.000)$ $\mathrm{BP}$ measurement between males and females; however, the percentages of high systolic and diastolic BP were equal in both genders.

\subsection{Laboratory results}

Mean (SD) $\mathrm{HbA}_{1 \mathrm{c}}$ level was 5.30 (0.41) \% without statistically significant difference between males and females (independent t-test; $\mathrm{p}=0.773$ ). On the other hand, a statistically significant difference was observed in mean (SD) FBG between males $\{3.80(1.18)\}$ and females $\{4.01(0.90)\}$, (independent $t$-test; $\mathrm{p}=0.006)$. Considering HbA $\mathrm{H}_{1 \mathrm{c}}$ level, the prevalence of prediabetes was 14.9\%, identically in males (14.9\%) and females (14.9\%), (Chi-square test; $\mathrm{p}=0.998)$; whereas, according to FBG, prediabetes, indicated by IFG, was diagnosed in $2.3 \%$ of the participants $(1.4 \%$ in males and $3.9 \%$ in females; $\mathrm{p}=0.103)$. Thus, the prevalence $(95 \%)$ of prediabetes was $16.3 \%(12.9 \% ; 20.1 \%)$.

Table 2 Result of laboratory tests by gender

\begin{tabular}{|c|c|c|c|c|}
\hline Parameter & Total $(N=436)$ & $\operatorname{Men}(\mathrm{N}=283)$ & Women $(\mathrm{N}=153)$ & p-value \\
\hline \multicolumn{5}{|l|}{ Glucose metabolism } \\
\hline HbA1c (\%) & $5.30(0.41)$ & $5.30(0.42)$ & $5.31(0.39)$ & 0.773 \\
\hline \multicolumn{4}{|l|}{ HbA1c (category), n (\%) } & \multirow{3}{*}{0.998} \\
\hline Normal $(<$ & $361(85.1)$ & $235(85.1)$ & $126(85.1)$ & \\
\hline High 0 & $63(14.9)$ & $41(14.9)$ & $22(14.9)$ & \\
\hline FBG (mmol/L) & $3.80(1.18)$ & $3.69(1.30)$ & $4.01(0.90)$ & $0.006^{*}$ \\
\hline \multicolumn{4}{|l|}{ FBG (category), n (\%) } & \multirow{3}{*}{0.103} \\
\hline Normal & $420(97.7)$ & $273(98.6)$ & 147 (96.1) & \\
\hline IFG & $10(2.3)$ & $4(1.4)$ & $6(3.9)$ & \\
\hline Prediabetes, n (\%) & $71(16.3)$ & $43(15.2)$ & $28(18.3)$ & 0.402 \\
\hline \multicolumn{5}{|l|}{ Lipid metabolism } \\
\hline Triglyceride (mmol/L) & $1.20(0.84)$ & $1.35(0.93)$ & $0.93(0.53)$ & $0.000^{*}$ \\
\hline HDL (mmol/L) & $1.39(0.31)$ & $1.31(0.27)$ & $1.53(0.32)$ & $0.000^{*}$ \\
\hline
\end{tabular}

Values are mean (standard deviation) unless indicated otherwise. The $t$ test was used for continuous variables and the chi-square test for categorical variables. HDL: high-density lipoprotein cholesterol; HbA1c: glycated hemoglobin A1c; FBG: fasting blood glucose; IFG: impaired fasting blood glucose; * statistically significant result ( $\mathrm{p}$-value $<0.05$ ).

Lipid metabolism profile showed that males had higher levels of triglyceride \{mean $(\mathrm{SD})=1.35(0.93)$ versus 0.93 (0.53) $\mathrm{mmol} / \mathrm{L} ; \mathrm{p}=0.000\}$ and lower levels of HDL $\{1.31(0.27)$ versus $1.53(0.32) \mathrm{mmol} / \mathrm{L} ; \mathrm{p}=0.000\}$, as compared to females, 
respectively. Males were more likely to have hypertriglyceridemia (23.7\% versus 5.1\%; $\mathrm{p}=0.000$ ) and less likely to have reduced HDL cholesterol (16.6\% versus 25.0\%; p=0.032), as compared to females, respectively (Table 2).

\subsection{Diagnosis and prevalence of metabolic syndrome}

According to diagnostic criteria, MetS was diagnosed in 46 among the 436 participants prevalence $(95 \% \mathrm{CI})=10.6 \%$ (7.80\%; 13.8\%)\}; 35 (8.0\%) had 3 abnormalities and 11 (2.5\%) had 4 abnormalities. The prevalence of MetS was relatively higher among males (11.7\%) than females (8.5\%); however, the difference was not statistically significant $(\mathrm{p}=0.305)$. Abdominal obesity was the most frequent abnormality, detected in $60.6 \%$, followed by high BP in $25.0 \%$. Hypertriglyceridemia was more prevalent among males (22.6\%) as compared to females (5.9\%), p=0.000). While reduced HDL was more prevalent among females (26.1\%) as compared to male (17.9\%), p=0.044 (Table 3).

Table 3 Diagnosis of metabolic syndrome by gender

\begin{tabular}{|c|c|c|c|c|}
\hline Parameter & Total $(N=436)$ & $\operatorname{Men}(\mathrm{N}=283)$ & Women $(\mathrm{N}=153)$ & p-value \\
\hline High BP & $109(25.0)$ & $76(26.9)$ & $33(21.6)$ & 0.224 \\
\hline Abdominal obesity & $264(60.6)$ & $165(58.3)$ & $99(64.7)$ & 0.192 \\
\hline Elevated triglyceride & $72(16.7)$ & $63(22.6)$ & $9(5.9)$ & $0.000 *$ \\
\hline Reduced HDL cholesterol & $90(20.8)$ & $50(17.9)$ & $40(26.1)$ & $0.044^{*}$ \\
\hline \multicolumn{5}{|c|}{ Number of abnormalities in one patient } \\
\hline 0 & $108(24.8)$ & $69(24.4)$ & $39(25.5)$ & \multirow{5}{*}{0.562} \\
\hline 1 & $167(38.3)$ & $108(38.2)$ & $59(38.6)$ & \\
\hline 2 & $115(26.4)$ & $73(25.8)$ & $42(27.5)$ & \\
\hline 3 & $35(8.0)$ & $27(9.5)$ & $8(5.2)$ & \\
\hline 4 & $11(2.5)$ & $6(2.1)$ & $5(3.3)$ & \\
\hline Metabolic syndrome & $46(10.6)$ & $33(11.7)$ & $13(8.5)$ & 0.305 \\
\hline
\end{tabular}

Values are frequency (percentage), and percentages are calculated on columns. BP: blood pressure; HDL: high-density lipoprotein; ${ }^{*}$ statistically significant result ( $p$-value<0.05); test used chi-square test

\subsection{Diagnostic significance of waist circumference, waist-to-hip ratio and body mass index in metabolic syndrome}

In ROC curve analysis, waist circumference showed fair accuracy to detect MetS in total population $\{$ AUC (95\%CI) $=0.746$ $(0.678 ; 0.814) ; p=0.000\}$, males $\{$ AUC $(95 \% \mathrm{CI})=0.756(0.686 ; 0.827) ; p=0.000\}$ and females $\{$ AUC $(95 \% \mathrm{CI})=0.720$ (0.587; 0.854); $\mathrm{p}=0.009\}$ (Figure 1). Comparatively, waist-to-hip ratio showed lower diagnostic accuracy in detecting MetS, with AUC ranging from 0.655 (poor) in males to 0.713 (fair) in females (Figure 2). Likewise, BMI (Figure 3) was reported to be a poor diagnostic test for MetS in females (AUC=0.679), although it was fair in males $(A U C=0.716)$.

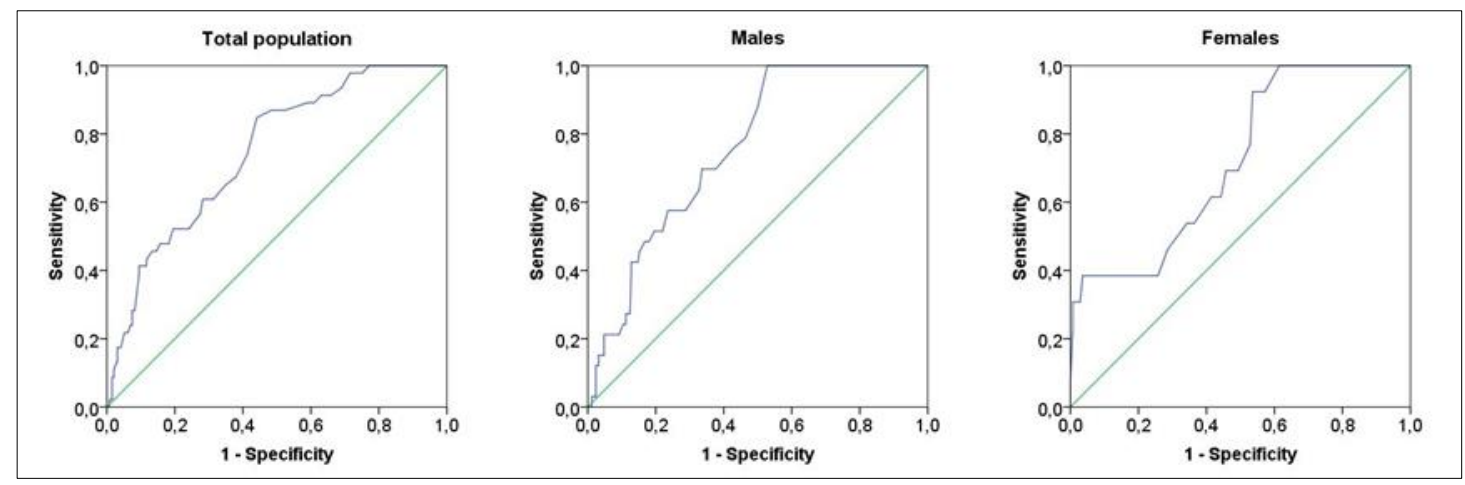




\begin{tabular}{|c|c|c|c|c|}
\hline Population & AUC & \multicolumn{2}{|c|}{ 95\%CI } & p-value \\
\hline Total population & 0.746 & 0.678 & 0.814 & $0.000^{*}$ \\
\hline Males & 0.756 & 0.686 & 0.827 & $0.000^{*}$ \\
\hline Females & 0.720 & 0.587 & 0.854 & $0.009^{*}$ \\
\hline
\end{tabular}

AUC: Area under the curve; CI: confidence interval; ${ }^{*}$ statistically significant result $(\mathrm{p}<0.05)$

Figure 1 Diagnostic value of waist circumference in metabolic syndrome (ROC curve analysis)
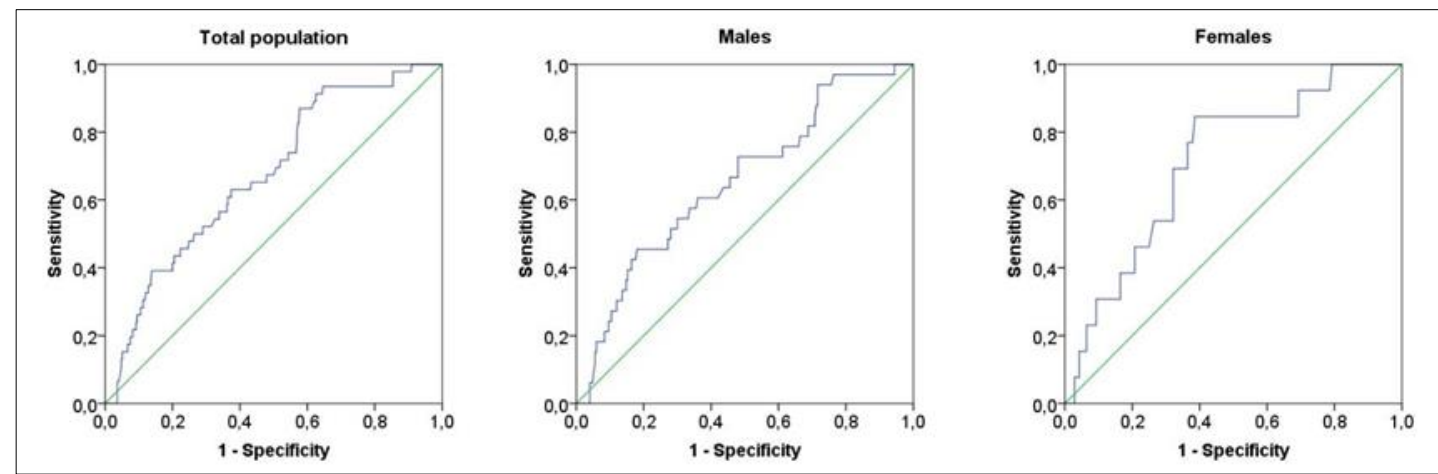

\begin{tabular}{|c|c|c|c|c|}
\hline Population & AUC & \multicolumn{2}{|c|}{$95 \%$ CI } & p-value \\
\hline Total population & 0.673 & 0.596 & 0.750 & $.000^{*}$ \\
\hline Males & 0.655 & 0.557 & 0.753 & $.004^{*}$ \\
\hline Females & 0.713 & 0.580 & 0.946 & $.011^{*}$ \\
\hline
\end{tabular}

Figure 2 Diagnostic value of waist-to-hip ratio in metabolic syndrome (ROC curve analysis)
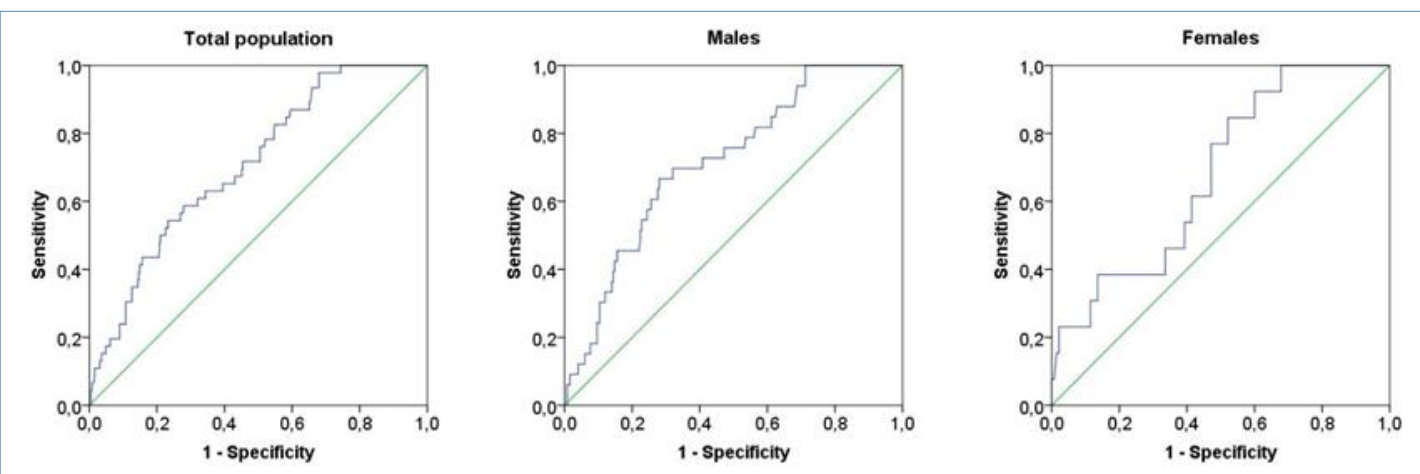

\begin{tabular}{|l|c|c|c|c|}
\hline \multicolumn{1}{|c|}{ Population } & AUC & \multicolumn{2}{c|}{ 95\%CI } & p-value \\
\hline Total population & 0.707 & 0.635 & 0.779 & $0.000^{*}$ \\
\hline Males & 0.716 & 0.630 & 0.802 & $0.000^{*}$ \\
\hline Females & 0.679 & 0.546 & 0.813 & $0.033^{*}$ \\
\hline
\end{tabular}

AUC: Area under the curve; CI: confidence interval; ${ }^{*}$ statistically significant result $(p<0.05)$.

Figure 3 Diagnostic value of body mass index in metabolic syndrome (ROC curve analysis) 


\section{Determining the optimal cut-off values for identifying metabolic syndrome}

Waist circumference, waist-to-hip ratio, and BMI were analyzed as screening tests for MetS in total population, as well as in men and women separately. Thus, the highest sensitivity possible was regarded to determine the respective optimal cut-off values, using the best value of Youden J index value \pm 0.050 . Results of this analysis including cut-off values of the three tests with their respective sensitivity, specificity, and Youden J index are presented in Table 4. Also, OR $(95 \% \mathrm{CI})$ of the prevalence of metabolic syndrome in exposed versus non-exposed population were calculated and presented in the same table. In males, a waist circumference $\geq 93.5 \mathrm{~cm}$ is likely to be detecting MetS with $100 \%$ sensitivity and $47.2 \%$ specificity; whereas, optimal waist-to-hip $(\geq 0.91)$ ratio and BMI $\left(\geq 28.7 \mathrm{~kg} / \mathrm{m}^{2}\right)$ cut-offs had lower diagnostic values; with $72.7 \%$ and $69.7 \%$ sensitivity and $52.0 \%$ and $66.8 \%$ specificity, respectively. In females, optimal waist circumference cut-off was determined as $\geq 83.5 \mathrm{~cm}$, showing $92.3 \%$ sensitivity and $46.4 \%$ specificity. Whereas, the optimal waist-to-hip ratio $(\geq 0.84)$ and BMI $\left(\geq 26.0 \mathrm{~kg} / \mathrm{m}^{2}\right)$ cut-offs had lower diagnostic values, with $84.6 \%$ each sensitivity and $61.4 \%$ and $47.9 \%$ specificity, respectively. Additionally, by reference to cut-offs, increased waist circumference was associated with the highest OR of metabolic syndrome both in males (OR=59.9) and females (10.4); by comparison to waist-to-hip ratio and BMI.

\subsection{Factors and predictors of metabolic syndrome}

Individuals with MetS had relatively older age $\{$ mean $(S D)=35.91$ (12.53) versus 30.36 (9.15); $p=0.000\}$ by reference to those without metabolic syndrome. Other sociodemographic factors associated with MetS included marital status $(p=0.003)$ and educational attainment $(p=0.004)$; that is the prevalence of MetS was higher among married individuals as well as those with low educational attainment when compared to their counterparts (Table 5). Metabolic syndrome was also associated with prediabetes, showing $19.7 \%$ versus $8.8 \%$ of prevalence among people with prediabetes versus those without, respectively $(\mathrm{p}=0.006)$ (Figure 4$)$.

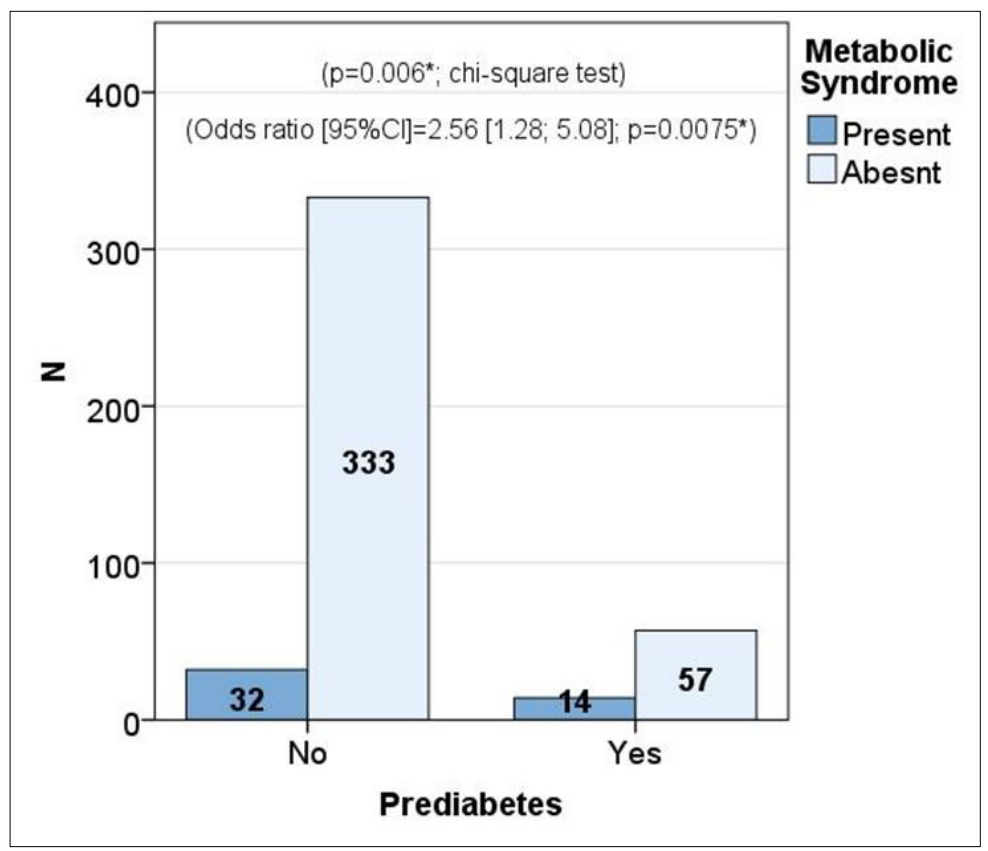

Figure 4 Correlation of metabolic syndrome with prediabetes

Caption: Bars represent the number of patients with (dark blue) and without (light blue) metabolic syndrome among those who have versus those who do not have prediabetes. There is higher prevalence of metabolic syndrome among people with prediabetes as compared to those without prediabetes (OR [95\%CI=2.56 [1.28; 5.08]; $\mathrm{p}=0.0075$ ).

In multivariate logistic regression (Table 6), extended waist circumference was the strongest predictor of MetS $\{0 R$ $(95 \% \mathrm{CI})=3.75(1.30 ; 10.81) ; \mathrm{p}=0.014\}$, followed by the presence prediabetes $\{\mathrm{OR}(95 \% \mathrm{CI})=2.31(1.06 ; 5.04) ; \mathrm{p}=0.035\}$. However, waist-to-hip ration and BMI were not significant predictors of metabolic syndrome. Further, the high educational level was a significant predictor for metabolic syndrome $\{\mathrm{OR}(95 \% \mathrm{CI})=0.34(0.12 ; 0.99)$; $\mathrm{p}=0.047\}$; while age and marital status were not significant. 
Table 4 Optimal cutoff values for identifying metabolic syndrome by the presence of at least one of the three risk factors among adult men and women

\begin{tabular}{|c|c|c|c|c|c|c|c|c|c|}
\hline Group & \multicolumn{3}{|c|}{ Total population } & \multicolumn{3}{|c|}{ Males } & \multicolumn{3}{|c|}{ Females } \\
\hline Risk factor & WC & W:H & BMI & WC & $\mathrm{W}: \mathbf{H}$ & BMI & WC & W:H & BMI \\
\hline Cutoff value & 93.5 & 0.86 & 26.0 & 93.5 & 0.91 & 28.7 & 83.5 & 0.84 & 26.0 \\
\hline Sensitivity & $84.8 \%$ & $87.0 \%$ & $82.6 \%$ & $100.0 \%$ & $72.7 \%$ & $69.7 \%$ & $92.3 \%$ & $84.6 \%$ & $84.6 \%$ \\
\hline Specificity & $55.9 \%$ & $42.3 \%$ & $44.9 \%$ & $47.2 \%$ & $52.0 \%$ & $66.8 \%$ & $46.4 \%$ & $61.4 \%$ & $47.9 \%$ \\
\hline Youden J index & 0.407 & 0.293 & 0.275 & 0.472 & 0.247 & 0.365 & 0.387 & 0.460 & 0.325 \\
\hline Odds-ratio $(95 \% \mathrm{CI})$ & $\begin{array}{l}7.06 \\
(3.08 ; 16.18)\end{array}$ & $\begin{array}{l}4.21 \\
(1.74 ; 10.17)\end{array}$ & $\begin{array}{l}3.91 \\
(1.78 ; 8.59)\end{array}$ & $\begin{array}{l}59.9 \neq \\
(3.63 ; 988.8)\end{array}$ & $\begin{array}{l}2.80 \\
(1.25 ; 6.26)\end{array}$ & $\begin{array}{l}4.55 \\
(2.07 ; 9.99)\end{array}$ & $\begin{array}{l}10.4 \\
(1.32 ; 82.16)\end{array}$ & $\begin{array}{l}7.78 \\
(1.66 ; 36.41)\end{array}$ & $\begin{array}{l}5.05 \\
(1.08 ; 23.6)\end{array}$ \\
\hline p-value & $<0.0001^{*}$ & $0.0014^{*}$ & $0.0007^{*}$ & $0.0042^{*}$ & $0.0123^{*}$ & $0.0002^{*}$ & $0.0264^{*}$ & $0.0092^{*}$ & $0.0397^{*}$ \\
\hline
\end{tabular}

WC: Waist circumference $(\mathrm{cm}): \mathrm{W}: \mathrm{H}$ : waist-to-hip ratio; BMI: body mass index $\left(\mathrm{kg} / \mathrm{m}^{2}\right)$; cut-off values were selected considering the highest sensitivity for the best Youden J index \pm 0.050 ; $\neq$ odd ratio was computed by adding 0.5 to all contingency table cells to correct the presence of null values in denominator (Pagano \& Gauvreau, 2000; Deeks \& Higgins, 2010) 
Table 5 Demographic factors of metabolic syndrome

\begin{tabular}{|c|c|c|c|}
\hline \multirow{2}{*}{ Factor / category } & \multicolumn{2}{|c|}{ Metabolic syndrome } & \multirow{2}{*}{ p-value } \\
\hline & Absent $(\mathrm{N}=390)$ & Present $(\mathrm{N}=46)$ & \\
\hline \multicolumn{4}{|c|}{ Sociodemographic factors } \\
\hline Age (years); mean (SD) & $30.36(9.15)$ & $35.91(12.53)$ & $0.000 *$ \\
\hline \multicolumn{4}{|l|}{ Gender } \\
\hline Male & $250(88.3)$ & $33(11.7)$ & \multirow{2}{*}{0.305} \\
\hline Female & $140(91.5)$ & $13(8.5)$ & \\
\hline \multicolumn{4}{|l|}{ Marital status } \\
\hline Single & $202(94.0)$ & $13(6.0)$ & \multirow{2}{*}{$0.003^{*}$} \\
\hline Married & $188(85.1)$ & $33(14.9)$ & \\
\hline \multicolumn{4}{|l|}{ Educational attainment } \\
\hline Up to primary & $21(70.0)$ & $9(30.0)$ & \multirow{5}{*}{$0.004^{*}$} \\
\hline Intermediate school & $17(89.5)$ & $2(10.5)$ & \\
\hline Secondary \& diplomas & $114(88.4)$ & $15(11.6)$ & \\
\hline Basic university degree & $221(91.7)$ & $20(8.3)$ & \\
\hline Post-graduate degree & $17(100.0)$ & $0(0.0)$ & \\
\hline \multicolumn{4}{|l|}{ Family Income per month } \\
\hline$\leq 3000 \mathrm{SR}$ & $54(91.5)$ & $5(8.5)$ & \multirow{5}{*}{0.320} \\
\hline$>3000-5000 \mathrm{SR}$ & $72(85.7)$ & $12(14.3)$ & \\
\hline$>5000-10000$ SR & $109(86.5)$ & $17(13.5)$ & \\
\hline$>10000-20000$ SR & $112(92.6)$ & $9(7.4)$ & \\
\hline$>20000 \mathrm{SR}$ & $43(93.5)$ & $3(6.5)$ & \\
\hline \multicolumn{4}{|l|}{ Physical activity at work } \\
\hline Office work & $78(91.8)$ & $7(8.2)$ & \multirow{4}{*}{0.547} \\
\hline Moderate & $106(87.6)$ & $15(12.4)$ & \\
\hline Considerable & $34(85.0)$ & $6(15.0)$ & \\
\hline Other & $172(90.5)$ & $18(9.5)$ & \\
\hline \multicolumn{4}{|l|}{ Home ownership } \\
\hline Rented & $15(83.3)$ & $3(16.7)$ & \multirow{3}{*}{0.592} \\
\hline Owned & $165(90.7)$ & $17(9.3)$ & \\
\hline Other & $210(89.0)$ & $26(11.0)$ & \\
\hline \multicolumn{4}{|l|}{ Ethnicity } \\
\hline Arabian tribes & $309(89.8)$ & $35(10.2)$ & \multirow{7}{*}{0.496} \\
\hline Sub-Saharan African & $18(94.7)$ & $1(5.3)$ & \\
\hline Mediterranean Arab & $35(85.4)$ & $6(14.6)$ & \\
\hline Indian subcontinent & $12(85.7)$ & $2(14.3)$ & \\
\hline South-east Asia & $3(75.0)$ & $1(25.0)$ & \\
\hline Central Asia & $2(66.7)$ & $1(33.3)$ & \\
\hline Other & $11(100.0)$ & $0(0.0)$ & \\
\hline
\end{tabular}


Table 6 Predictors of metabolic syndrome

\begin{tabular}{|c|c|c|c|c|}
\hline Predictor & Odds-ratio & \multicolumn{2}{|c|}{$95 \% \mathrm{CI}$} & p-value \\
\hline Age (years) & 1.01 & 0.97 & 1.05 & 0.722 \\
\hline \multicolumn{5}{|l|}{ Marital status } \\
\hline Single (ref) & - & - & - & - \\
\hline Married & 1.63 & 0.69 & 3.82 & 0.263 \\
\hline \multicolumn{5}{|l|}{ Educational attainment } \\
\hline Up to primary (ref) & - & - & - & 0.364 \\
\hline Intermediate school & 0.31 & 0.05 & 1.78 & 0.190 \\
\hline Secondary \& diplomas & 0.48 & 0.16 & 1.42 & 0.185 \\
\hline Basic university degree & 0.34 & 0.12 & 0.99 & $0.047^{*}$ \\
\hline Post-graduate degree & 0.00 & 0.00 & 0.00 & - \\
\hline \multicolumn{5}{|l|}{ Prediabetes } \\
\hline Absence (ref) & - & - & - & - \\
\hline Presence & 2.31 & 1.06 & 5.04 & $0.035^{*}$ \\
\hline \multicolumn{5}{|l|}{ Waist circumference } \\
\hline Normal (ref) & - & - & - & - \\
\hline Increased & 3.75 & 1.30 & 10.81 & $0.014^{*}$ \\
\hline \multicolumn{5}{|l|}{ Waist-to-hip ratio } \\
\hline Normal (ref) & - & - & - & - \\
\hline Increased & 2.00 & 0.74 & 5.42 & 0.171 \\
\hline \multicolumn{5}{|l|}{ BMI } \\
\hline Normal (ref) & - & - & - & - \\
\hline Increased & 1.29 & 0.48 & 3.50 & 0.618 \\
\hline
\end{tabular}

Test used: multivariate binary logistic regression, with presence of metabolic syndrome being the dependent variable. ${ }^{*}$ Statistically significant result $(p<0.05)$; CI: confidence interval; ref: reference category; BMI: body mass index.

\section{Discussion}

Screening all the eligible adults $(n=436)$, the majority $(83.7 \%)(n=365)$ were normal glycemic, and $(16.3 \%)(n=71)$ were prediabetics. Whereas, $10.6 \%$ of all eligible adult had MetS $(n=53)$. This was expected since most of the participants were young, with a mean age of years is 30.94 (SD 9.70) and highly educated. Advanced age and low education level were independently associated with increased likelihood of metabolic syndrome [17]. In addition to advanced age, it is a strong predictor of prediabetes [7].

However, on screen for the presence of MetS among prediabetes, 19.7\% $(n=14)$ of prediabetic person ( $n=71)$ were found to meet the MetS definition. This is expecting once a prediabetic state is associated with metabolic abnormalities. The study results showed that $36.2 \%$ of the screened population was overweight and almost one-third (29.4\%) were obese and about two-thirds (60.6\%) had abdominal obesity.

This study demonstrated that the prevalence of MetS among the overall studied population is less than the prevalence MetS among prediabetic individuals. However, MetS prevalence among prediabetic individual was almost same as of the previous study conducted in Jeddah [6]. These results suggest that the most of the screened population in the study had T2DM or prediabetes. Regarding the current study findings in comparison with the prevalence in other countries, 
MetS prevalence among all individuals was relevant to a study conducted in Asia. Although the impaired glucose metabolism is not common [15], the MetS prevalence among prediabetic person is almost similar to a study conducted to demonstrate that impaired glucose metabolism is one of the first two common component of MetS [16]. This suggests that impaired glucose metabolism play an important role in MetS prevalence.

In this study, the prevalence of prediabetes was more than the previous study conducted in Jeddah city [7]. This can support by the fact that the previous study used IFG alone in determining a prediabetic state; however, the current study used IFG, $\mathrm{HbA}_{1 \mathrm{c}}$, and both in the definition of prediabetes. $[18,19]$.

When the prevalence of MetS was considered among prediabetic patients, the prevalence was higher than MetS alone or prediabetes alone among the population studied. This can be expected because the component of MetS is more obvious in prediabetic state [20].

The prevalence of metabolic syndrome was relatively higher among males $(11.7 \%)$ than females (8.5\%); however, the difference was not statistically significant $(\mathrm{p}=0.305)$ in this study. Some studies have shown that Mets is common in male as compared to females [12]. However, most of the studies have demonstrated that MetS is common among women as compared to men $[11,13,16,21]$.

In this study, after adjustment of IFG, abdominal obesity was the most frequent abnormality detected in $60.6 \%$, followed by high BP in 25.0\%. Hypertriglyceridemia was more prevalent among males (22.6\% versus $5.9 \%$; $\mathrm{p}=0.000)$ as compared to females, while reduced HDL was more prevalent among females (26.1\% versus $17.9 \%$; $=0.044)$ as compared to males [15].

In multivariate logistic regression, extended waist circumference was the strongest predictor of MetS (OR [95\%CI] $=3.75[1.30 ; 10.81] ; p=0.014$ ), followed by the presence prediabetes (OR [95\%CI]=2.31 [1.06; 5.04]; $p=0.035$ ). Further, high educational level was a significant protective predictor for MetS (OR [95\%CI]=0.34 [0.12; 0.99]; p=0.047); while age and marital status were not significant. Most of the other studies reflect the same fact of that age and low education were associated with MetS[11,12]. Other study showed that MetS prevalence is affected by older age, but not by education level [14].

The second objective of the present study was to determine the appropriate waist circumference cutoff value for identifying a person's risk for the MetS.

The present study reported a waist circumference $\geq 93.5 \mathrm{~cm}$ is likely to be detecting MetS in males with $100 \%$ sensitivity and $47.2 \%$ specificity. Whereas, in females, optimal waist circumference cut-off was determined as $\geq 83.5 \mathrm{~cm}$, showing $92.3 \%$ sensitivity and $46.4 \%$ specificity.

The waist circumference showed fair accuracy to detect MetS in total population (AUC [95\%CI]=0.746 [0.678; 0.814]; $\mathrm{p}=0.000$ ), males (AUC [95\%CI] $=0.756$ [0.686; 0.827]; $\mathrm{p}=0.000$ ) and females (AUC [95\%CI] $=0.720$ [0.587; 0.854]; $\mathrm{p}=0.009$ ). This point is close to estimated cut-off point in recent study conducted in Saudi Arabia for men, but is slightly less than estimated cut-off point demonstrated for women [22]. However, it is different from other studies in other countries $[14,15,21]$.

Strength of the study: It gave figure of the prevalence of MetS and some important health related characteristics. The study results will help definine the local cut-off point for prediction of MetS and improve early detection of MetS. Further, this study assessed the motives for screening for a high risk of T2DM and CVD, with simple tool.

Limitations of the study: It is the study conducted in one city and as any cross-sectional study, it measures prevalence rather than incidence and it is susceptible to bias due to few responses.

\section{Conclusion}

Metabolic syndrome was reported in approximately in one out of nine patients attending PHC in Jeddah. The rate was almost equal among males and females. Waist circumference is a strong predictor for MetS, showing good associations and fair diagnostic utility. People with extended waist circumference ( $\geq 93.5 \mathrm{~cm}$ in males and $\geq 83.5 \mathrm{~cm}$ in females) are exposed to more than 10-fold odds risk of developing MetS. These cut-off values can be used as a screening test with 
93\% to $100 \%$ sensitivity. Further, given the simplicity of the test, auto-measurement of waist circumference should be encouraged to increase the chances of early detection and management of MetS.

\section{Compliance with ethical standards}

\section{Acknowledgments}

The authors acknowledge the scientific research at Ministry of Health, Jeddah, Saudi Arabia.

\section{Disclosure of conflict of interest}

The authors declare that they have no conflicts of interest.

\section{Statement of informed consent}

Informed consent was obtained from all individual participants included in the study.

\section{References}

[1] Cho L. Metabolic syndrome. Singapore Med J. 2011; 52(11): 779-85.

[2] Cornier MA, Dabelea D, Hernandez TL, Lindstrom RC, Steig AJ, Stob NR, et al. The metabolic syndrome. Endocr Rev. 2008; 29(7): 777-822.

[3] Alireza Delavari, Md1 Mohammad Hossein Forouzanfar, Md, Mph, Phd1 2, Siamak Alikhani, Md, Mph3 Afsaneh Sharifian, Md4 Roya Kelishadi M. First Nationwide Study of the Prevalence of the Metabolic Syndrome and Optimal Cutoff Points of Waist Circumference in the Middle East. Diabetes Care. 2009; 32(6): 1092-7.

[4] Sliem HA, Ahmed S, Nemr N, El-Sherif I. Metabolic syndrome in the Middle East. Indian J Endocrinol Metab. 2012; 16(1): 67-71.

[5] Alberti KG, Eckel RH, Grundy SM, Zimmet PZ, Cleeman JI, Donato KA, et al. Harmonizing the metabolic syndrome: a joint interim statement of the Association for the Study of Obesity. Circulation. 2009; 120(16): 1640-5.

[6] Bahijri SM, Al Raddadi RM. The importance of local criteria in the diagnosis of metabolic syndrome in Saudi Arabia. Ther Adv Endocrinol Metab. 2013; 4(2): 51-9.

[7] Bahijri SM, Jambi HA, Al Raddadi RM, Ferns G, Tuomilehto J. The Prevalence of Diabetes and Prediabetes in the Adult Population of Jeddah, Saudi Arabia- A Community-Based Survey. Barengo NC, editor. PLoS One [Internet]. 1 Apr 2016; 11(4): e0152559.

[8] Katzmarzyk PT, Janssen I, Ross R, Church TS, Blair SN. The importance of waist circumference in the definition of metabolic syndrome: prospective analyses of mortality in men. Diabetes Care. 2006; 29(2): 404-9.

[9] Alkahtani S, Elkilany A, Alhariri M. Association between sedentary and physical activity patterns and risk factors of metabolic syndrome in Saudi men: A cross-sectional study. BMC Public Health. BMC Public Health. 2015; 15(1): 1234.

[10] Aljohani NJ. Metabolic syndrome: Risk factors among adults in Kingdom of Saudi Arabia. Fam Community Med. 2014; 21(3): 170-175.

[11] Krishnadath ISK, Toelsie JR, Hofman A, Jaddoe VW V. Ethnic disparities in the prevalence of metabolic syndrome and its risk factors in the Suriname Health Study: a cross-sectional population study. BMJ Open. 2016; 6(12): e013183.

[12] Fernández-Bergés D, Cabrera de León A, Sanz H, Elosua R, Guembe MJ, Alzamora M, et al. Metabolic syndrome in Spain: prevalence and coronary risk associated with harmonized definition and WHO proposal. DARIOS study. Rev española Cardiol (English ed). 2012; 65(3): 241-8.

[13] Kaduka LU, Kombe Y, Kenya E, Kuria E, Bore JK, Bukania ZN, et al. Prevalence of Metabolic Syndrome among an Urban Population in Kenya. Diabetes Care. 2012; 35(4): 887-93. 
[14] Magalhaes P, Capingana DP, Mill JG. Prevalence of the metabolic syndrome and determination of optimal cut-off values of waist circumference in university employees from Angola. Cardiovasc J Afr. 2014; 25(1): 27-33.

[15] Nurjono M, Lee J. Waist circumference is a potential indicator of metabolic syndrome in Singaporean Chinese. Ann Acad Med Singapore. 2013; 42(5): 241-5.

[16] Mabry RM, Winkler EAH, Reeves MM, Eakin EG, Owen N. Associations of Physical Activity and Sitting Time With the Metabolic Syndrome Among Omani Adults. Obesity. 2012; 20(11): 2290-5.

[17] Xavier Moore J, Chaudhary N, Akinyemiju T. Metabolic Syndrome Prevalence by Race/Ethnicity and Sex in the United States, National Health and Nutrition Examination Survey, 1988-2012. Natl Heal Nutr Exam Surv Prev Chronic Dis. 2017; 14: 1-16.

[18] Kim KS, Kim SK, Lee YK, Park SW, Cho YW. Diagnostic value of glycated haemoglobin (HbA1c) for the early detection of diabetes in high-risk subjects. Diabet Med. 2008; 25(8): 997-1000.

[19] Du TT, Yin P, Zhang JH, Zhang D, Shi W, Yu XF. Comparison of the performance of HbA1c and fasting plasma glucose in identifying dysglycaemic status in Chinese high-risk subjects. Clin Exp Pharmacol Physiol. 2013; 40(2): 63-8.

[20] Mandob DE, Sabine P. Metabolic Syndrome Prevalence among Prediabetic and Normoglucotolerant Women. J Diabetes Metab. 2016; 7(10).

[21] Guo H, Liu J, Zhang J, Ma R, Ding Y, Zhang M, et al. The prevalence of metabolic syndrome using three different diagnostic criteria among low earning nomadic kazakhs in the far northwest of China: New cut-off points of waist circumference to diagnose mets and its implications. PLoS One. 2016; 11(2): 1-13.

[22] Al-Rubean K, Youssef AM, Al Farsi Y, Al-Sharqawi AH, Bawazeer N, Al Otaibi MT, et al. Anthropometric cutoff values for predicting metabolic syndrome in a Saudi community: From the SAUDI-DM study. Ann Saudi Med. 2017; 37(1): 21-30. 